\title{
Macroalocações de Recursos em Saúde por INTERMÉDIO dA ATIVIDADE JURÍDICO-PROCESSUAL: IMPLICAÇÕES BIOÉTICAS
}

\author{
JUDICIALLY ORDERED HEALTH FUNDS MACRO-
} ALLOCATIONS: BIOETHICS IMPLICATIONS

Sergio Domingos Pittelli(*)
Daniel Romero Muñoz
$(\star *)$

\section{RESUMO}

A finalidade deste artigo é descrever a situação relativa à macroalocação de recursos de origem jurídico-processual gerada no Brasil pela nova conformação jurídico-política derivada da Constituição Federal de 1988 e analisar suas implicações na esfera da bioética. No que tange à bioética, a questão é analisada sob o ponto de vista dos princípios da beneficência, autonomia e justiça. Conclui-se que a situação descrita implica em violação do princípio da justiça pelo uso abusivo do princípio da beneficência. Conclui-se ainda que o abuso se concretiza pela ausência de participação da sociedade nas decisões judiciais, o que afasta o componente solidariedade. Conclui-se, paralelamente, que é necessário mudar a conformação jurídico-política com melhor definição dos poderes do juiz na esfera do Direito Sanitário e ainda que a situação reforça o modelo econômico que atrela os gastos em saúde aos interesses do mercado.

\section{Descritores}

Bioética; Conflito de Interesses; Custo do Atendimento; Programas Governamentais; Responsabilidade Social.

(*) Médico e Advogado, Especialista em Direito Sanitário pela Faculdade de Saúde Pública da USP, Especializado em administração de saúde pela FGV - PROAHSA, Rua Alberto Faria, 91 - CEP 05459-000 - São Paulo — SP. E-mail: pittelli@uol.com.br.

$\left.{ }^{\star \star}\right)$ Professor Livre-docente chefe da Disciplina de Medicina Legal e Bioética do Departamento de Medicina Legal, Ética Médica e Medicina Social e do Trabalho da Faculdade de Medicina da USP Rua Teodoro Sampaio, 115 - CEP 05405-000 - SP. Entrada: 2.7.2003. Aprovado: 24.9.2003. 


\section{ABSTRACT}

This paper addresses problems relating to judicially ordered health funds allocation as well as its bioethics implications. The situation is consequence of the new juridical-political order derived from de 1988 Federal Constitution. Regarding bioethics, the analysis is based on the Principles of Beneficence, Autonomy and Justice. The authors conclude that the described situation gives raise to violation of the Justice Principle by the abusive utilization of the Beneficence Principle. They also conclude that the abuse is rendered by the absence of participation of the whole society on judicial decisions, circumstance that implies the dismissal of social solidarity. They finally conclude about the necessity of changings in the juridical-political order with a better definition of the competencies of the judges in the field of Health Law and that the present situation reinforces an economic model that harness the health funds allocation to market concerns.

\section{Key-words}

Bioethics, Conflict of Interest; Cost of Illness, Government Programs, Social Responsibility.

\section{INTRODUÇÃO}

Neste texto avaliaremos, segundo os princípios e conceitos da Bioética, algumas questões novas trazidas ao cenário das políticas públicas de saúde pela nova ordem jurídico-política emanada da Constituição Federal de 1988.

Os elementos que compõem o conjunto de fatores responsáveis pela situação a ser analisada, são: 1. o novo estatuto jurídico do direito à saúde, consoante o conformou os arts. 6 e 196 a 200 da Carta Magna e subseqüente legislação infraconstitucional (Lei n. 8.080/90 - Lei Orgânica da Saúde); 2. a ampliação proporcionada pelo texto constitucional às funções e poderes do Ministério Público, sobretudo no que se refere à defesa dos Direitos Difusos e Coletivos; 3. o novo estatuto conferido ao direitos do consumidor, calcado na Constituição e subseqüente legislação infra-constitucional (Lei n. 8.078/90 - Código de Defesa do Consumidor); 4. o reforço de competências processuais já existentes na ordem constitucional anterior, relativas às Ações Civis Públicas (Lei n. 7.347/85).

Dos elementos acima citados, o principal, para os fins deste texto, é, indubitavelmente, o enunciado do art. 196 da Constituição Federal, ao qual restringiremos nossa análise.

O entendimento sobre de que forma referido enunciado participa da conformação da situação a ser analisada calca-se nos conceitos de direitos humanos de primeira geração e de segunda geração (Dallari ${ }^{i, 2,3}$, Pittelli ${ }^{8}$ ). 
Os direitos de primeira geração correspondem aos chamados "direitos civis", vindos a lume com o Estado liberal iluminista do século XVIII. Têm características essencialmente limitadoras ("direitos de vedação") de eventuais violações de direitos da esfera individual do cidadão.

Os direitos de segunda geração, também chamados de "direitos sociais", surgiram a partir de fins do século XIX, sob a égide do Estado Social. Contrariamente aos primeiros, caracterizam-se por ser de natureza prestacional, ou seja, o Estado é chamado a prestar algo à coletividade (e.g.: saúde, habitação, previdência social, etc.) e não a (simplesmente) impedir que haja violações de direitos individuais. Tais direitos aparecem sob forma de normas inseridas nas chamadas "constituições sociais", no início do século XX. Na Constituição Federal brasileira de 1988 os direitos sociais achamse listados no art. $6^{\circ}$ e a saúde é tratada nos arts. 196 a 200, conforme já registrado.

Os modos pelos quais o Direito se presta a cumprir esta nova função são variados e complexos.

Para os fins que interessam a este texto, restringir-nos-emos a considerações sobre apenas um destes mecanismos. Isto posto, identificamolo como a mudança de concepção, operada pela doutrina e jurisprudência, segundo a qual as normas constitucionais deixaram de possuir caráter meramente programático e/ou declarativo (que tradicionalmente lhes era atribuído) e assumiram caráter verdadeiramente impositivo, ou, dito de outra forma, de exigibilidade imediata (Dallari ${ }^{1}, S^{2}$ Siva $^{9}$ ). Tal circunstância aparece por vez primeira nas constituições portuguesa de 1976 e espanhola de $1978^{1}$ e foi consignada, por doutrina e jurisprudência, ao supra-citado comando constitucional insculpido no art. 196 da nossa Constituição: a saúde é direito de todos e dever do Estado.

Essa assunção da condição de exigibilidade imediata da norma constitucional, associada aos demais elementos conformadores acima citados, criou o que se pode chamar de uma nova "cultura jurídico - processual" no Brasil, caracterizada pela busca imediata da satisfação de direitos individuais e coletivos na área da saúde, seja indiretamente, por intermédio do uso do remédio processual, ou seja, pelo constrangimento do Estado à satisfação de direitos reclamados utilizando-se para tanto do processo judicial e conseqüente intervenção do Poder Judiciário, seja diretamente por via administrativa (mediante formas legítimas de pressão política), esta última, entretanto, altamente estimulada pela quase inexorabilidade da derrota do poder público nas demandas judiciais da espécie.

Embora a uma primeira análise, e de um ponto de vista focado na evolução do Direito no sentido de tornar-se instrumento de mudanças sociais, essa nova situação seja jubilosa, o exercício efetivo dos direitos daí advindos revelou, segundo nosso entendimento, aspectos problemáticos, caracteriza- 
dos, grosso modo e de forma preliminar, pelo que poderíamos chamar de intervenção "abusiva" do Poder Judiciário na condução de políticas públicas na área da saúde, com conseqüências das quais a mais óbvia e importante é a determinação de gastos de fundos públicos à revelia da vontade do Administrador, gastos estes que podem vir (como na verdade, parece que já começa a acontecer) a adquirir proporções orçamentárias incompatíveis com as normas da boa administração. Uma segunda conseqüência é representada pela possível inequidade na distribuição de recursos públicos, conforme será demonstrado.

Um outro e distinto elemento componente desta situação seria constituído pelo uso de todo este aparato teórico doutrinário e legal com a finalidade de satisfazer interesses materiais da indústria de produtos de saúde, especialmente a indústria farmacêutica.

O objeto deste artigo, portanto, é constituído pela discussão de aspectos bioéticos ligados a alocações de recursos determinadas pelo Poder Judiciário (ou sendo obtida administrativamente sob a perspectiva da utilização alternativa da via judicial) e, conseqüentemente, à revelia da vontade do Administrador, criando o risco, por um lado, de comprometer a viabilidade da administração dos recursos públicos e por outro lado, de gerar situação de distribuição não equitativa desses recursos.

Os valores em conflito, portanto, que justificam a reflexão na esfera da bioética são o direito inalienável à saúde, contraposto à necessidade de garantir a viabilidade administrativa e a equidade na distribuição de recursos.

Faremos, a seguir, breve relato dos fatos que constituem o objeto de análise deste texto.

\section{DESCRIÇÃO DOS FATOS}

Inicialmente, cumpre esclarecer ser difícil a coleta de dados sistematizados sobre o assunto vez que a Secretaria de Estado da Saúde não possui sistema de registro de ações judiciais e seus efeitos.

Segundo Lucarelli5 (dados não publicados) no período que se estende de agosto de 1994 a outubro de 2002, foram protocoladas 1140 ações em face da Fazenda Pública do Estado de São Paulo com a finalidade de obrigar o Governo do Estado a dispensar alguma forma de cuidado de saúde (a imensa maioria, medicação de alto custo e procedimentos de alta complexidade) a pessoas ou grupos.

Trata-se de uma média aproximada de 140 ações por ano.

A tradução desta atividade judicial contra o Estado em valores pecuniários padece dos mesmos problemas acima apontados quando à sua identificação e quantificação. 
O autor em questão estimou um gasto de $\mathrm{R} \$ 16.000 .000,00$ no ano de $2002^{(1)}$. Para se ter uma idéia de proporções, o chamado "Programa Estadual de Assistência Farmacêutica Básica - Dose Certa" que fornece uma lista de 41 medicamentos básicos para a população de todo o Estado aplicou no mesmo ano a quantia de $\mathrm{R} \$ 87.500 .000,00$, o que implica em um gasto per capita de $\mathrm{R} \$ 2,92$. Já os dezesseis milhões estimados como gastos com ações judiciais, correspondentes a aproximadamente um quinto do valor acima, foram despendidos com algumas poucas centenas de pessoas apenas.

Esta relação seria ainda desproporcionalmente favorável ao grupo de ações judiciais, mesmo se levássemos em conta outros programas. O "Programa de Medicamentos de Alto Custo/Excepcionais" distribui 91 itens padronizados de medicação de alto custo para moléstias que requerem alta complexidade (transplantes e câncer, por exemplo). O montante deste programa para 2002 foi de $R \$ 179.880 .191,00$, ou seja, o montante aplicado em ações judiciais equivale a aproximadamente $10 \%$ dos gastos com este programa.

Uma situação mais dramática ainda se desvela da análise de grupos específicos de pacientes, sobretudo da Doença de Gaucher, moléstia que se caracteriza pela ausência congênita e de origem genética da enzima beta-galactosidase. A doença é incapacitante e limita a expectativa de vida.

Recentemente, foi sintetizada e comercializada a enzima cuja falta é responsável pela doença, circunstância que permitiu que os portadores ganhassem novo alento, com notória melhora da qualidade de vida, bem como aumento da expectativa de vida para níveis praticamente normais.

A tabela abaixo mostra a evolução do número de beneficiários e os correspondentes gastos total e per capita a partir de 2001.

Tabela 1. Gastos com fornecimento de Imiglucerase

\begin{tabular}{|c|c|c|c|}
\hline Ano & N. pacientes & Custo/capita (R\$) & Custo (R\$) \\
\hline 2001 & 82 & $19.389 .348,40$ & $236.455,46$ \\
\hline 2002 & 96 & $29.056 .861,75$ & $302.675,63$ \\
\hline 2003 & 112 & $44.165 .269,93$ & $394.332,75$ \\
\hline
\end{tabular}

Fonte: Secretaria Estadual da Saúde.

Tomando-se os valores para o ano 2002, constata-se um gasto total de $R \$ 29.056 .861,75$ que somados aos $R \$ 16.000 .000,00$ estima-

(1) Esta estimativa leva em conta apenas os valores gastos por ordem da sentença, não incluindo nenhum outro valor tal como custas de advogados, outros servidores, material, etc. 
dos por Lucarelli para as ações judiciais, perfazem um total aproximado de $\mathrm{R} \$ 45.000 .000,00$

Verificando dados orçamentários da Secretaria da Saúde para o mesmo ano, constatamos que foram gastos $R \$ 261.656 .205,51$ com o elemento "medicamentos e insumos farmacêuticos", donde se conclui que pouco mais de $17 \%$ deste elemento orçamentário foram gastos com ações judiciais ou programas que de alguma forma foram instituídos em decorrência da nova concepção de exigibilidade imediata da norma constitucional.

Ainda que se restrinja a análise acima aos dados oficiais (Tabela 1), obtém-se uma taxa de $10 \%$ do elemento "medicamentos ..." gastos com o programa de fornecimento da beta-galactosidase. Taxa semelhante é obtida se compararmos os valores respectivos para o ano 2003.

Se tomarmos o item "aplicações diretas" cujo valor é R\$1.202.908.142,52 como a melhor aproximação (se não o for efetivamente) do valor dos gastos diretos com a atividade-fim do órgão (prestação de serviços de saúde), chegamos a uma taxa aproximada de $4,1 \%$, do valor deste elemento orçamentário que não fica vinculada no momento da execução do orçamento.

Outros aspectos problemáticos, não estritamente monetários desta questão, são resumidamente e apenas a título de citação: 1. a imposição judicial de medicação ainda não autorizada pela autoridade sanitária brasileira (sendo costumeiro que se leve em conta, para tanto, o apenas e tão somente o licenciamento da nova droga pela FDA americana); 2 . indicações de drogas ou exames cuja eficácia ainda não está comprovada sendo exemplo disto a indicação de glivec para outras entidades nosológicas que não a forma mielóide crônica da leucemia. Um outro tipo de distorção relativamente freqüente é a aceitação de simples indicações médicas individuais, geralmente sob forma de simples prescrição em receituário, como fundamento da demanda.

Estes são, em breve síntese, os dados numéricos fáticos que justificam a escolha do objeto do presente texto.

\section{DISCUSSÃO}

A abordagem da questão comporta quatro aspectos sob os quais se deve desenvolver a análise: 1 . Sob uma óptica estritamente principialista, importando, no caso, os Princípios da Beneficência, Autonomia e Justiça ; 2. Da perspectiva das implicações bioéticas de alguns aspectos de práticas de saúde pública (mais especificamente de macro-alocações de recursos) e sua imbricação com o Princípio da Justiça; 3. Sob uma óptica estritamente jurídica; 4 . Da reprodução e perpetuação de um determinado modelo de saúde atrelado aos interesses do mercado. 
$\mathrm{Na}$ verdade, as duas últimas perspectivas acima mencionadas não se amoldam exatamente ao conceito de bioética e a rigor não deveriam constar de um texto como este. Entendemos, entretanto, que a discussão ficaria incompleta se não abordássemos o assunto também sob estas duas ópticas, ainda que de forma sucinta, como será feito, e como intróito a uma discussão futura, em texto próprio.

\section{A QUESTÃO PRINCIPIALISTA: DAS IMPLICAÇÕES RELATIVAS AOS PRINCÍPIOS DA BENEFICÉNCIA, AUTONOMIA E JUSTIÇA}

Inicialmente, cumpre declarar que concebemos Princípio da Beneficência em sua vertente de "dever independente e condicional (ou não absoluto")" ou seja, dentro da perspectiva de David Ross. Com isso, pretendemos não apenas afastar qualquer conotação relativa ao conceito de benevolência, mas principalmente acentuar o seu caráter de "prima facies duty" e, portanto, seu aspecto de condicionalidade.

Feito este esclarecimento inicial, impõe-se então concluir que, numa primeira perspectiva, toda e qualquer ação no sentido de prover tratamento adequado (incluída aí a incorporação de nova tecnologia, como se dá na totalidade dos exemplos citados acima), afeiçoa-se aos ditames do princípio ora em análise.

Aliás, entendemos que outra não é a inspiração do Legislador Constitucional ao conceber e positivar o citado art. 196 da Constituição Federal, estendendo a todos a garantia do direito à saúde.

Sob esta perspectiva, portanto, e numa primeira consideração, ao valer-se do Poder Judiciário para obter aquilo que, de outra forma, o Estado não thes estaria garantindo, os que assim agissem estariam se comportando de forma válida tanto do ponto de vista da ética quanto dos mais elementares princípios de cidadania.

O leitor atento, entretanto, já entendeu que o próximo passo desta discussão será verificar se não haveria um segundo dever (ou direito), tão ou mais forte que o primeiro, a contrapor-se a este.

Com efeito, dentro da perspectiva "rossiana" acima citada, Kipper e Clotet ${ }^{4}$ afirmam que "o princípio da beneficência tenta, num primeiro momento, a promoção da saúde e a prevenção da doença e, num segundo lugar, pesa os bens e os males buscando a prevalência dos primeiros". Citam a seguir exemplos de situações em que haveria limitações oponiveis ao exercício sem limites deste princípio. Todos os exemplos citados, entretanto, referem-se a situações clínicas individuais nas quais os limites ao exercício do Princípio da Beneficência são impostos pela violação ao Princípio da Autonomia, ou seja, violação ao direito à decisão autônoma do pró- 
prio sujeito (paciente) objeto das atividades clínicas que engendram reflexões bioéticas. Os autores não consideram, portanto, e s.m.j., a possibilidade de haver limitações a este princípio geradas por violações a direitos de terceiros, circunstância esta que implica em violação do Princípio da Justiça, conforme pretendemos demonstrar a seguir.

Antes de continuar, cumpre então declarar nosso entendimento de que a concepção de Justiça a que melhor se afeiçoa o princípio em pauta (para os fins desta discussão, pelo menos) é a de Rawls ${ }^{6,10}$.

Entendemos, portanto, e de forma simplificada, Justiça como manifestação da equidade e todos os seus corolários, do qual o mais importante para os fins deste texto é o constituído pela possibilidade de ações discriminativas, favorecendo os mais vulneráveis, nos termos que expõe Fortes (apud Pavonib): "...se resultar em benefícios compensatórios para cada um e particularmente para os membros menos favorecidos, menos afortunados da sociedade".

Fica claro, portanto, para os fins a que nos propomos e como declaração de nossa posição pessoal sobre o assunto, que o critério de Justiça, nos casos em que a ação é discriminativa, favorecendo grupos pequenos, deve atribuir peso importante ao fator vulnerabilidade dos grupos favorecidos.

Este critério isoladamente, entretanto, não é suficiente a nosso ver. Divisamos, com efeito, um outro critério que não foi explicitado por nenhum dos dois autores que citamos neste tópico (e até onde sabemos, por nenhum outro autor), mas que entendemos ser de suma importância. Referido critério é a origem ou fonte da ação discriminativa positiva: entendemos que esta deve provir do poder público (pelos mecanismos institucionais de decisão, ou seja, que envolvam ampla discussão de toda a sociedade civil, tanto em sede administrativa quanto legislativo-normativa) e não por exclusiva iniciativa dos próprios grupos interessados, ainda que estes satisfizessem o critério de vulnerabilidade e agissem por mecanismos legais. Tal entendimento, por sua vez, segundo nossa pessoal concepção, advém do fato de que a solidariedade (entendida como adesão da maior parte da sociedade) integra a natureza da Justiça (para os fins do objeto deste texto). Concluímos então que, para que ações discriminativas satisfaçam o Princípio da Justiça, devem satisfazer estes dois critérios: a vulnerabilidade dos favorecidos e a solidariedade, mas entendida esta última como participação ampla da sociedade na tomada de decisão da política discriminativa, a ser legitimada pelo desenvolver-se no nível da esfera pública.

Ao nosso ver a situação-problema objeto deste texto não atende ao segundo dos dois critérios acima citados (solidariedade).

Não nos deteremos no assunto neste momento, pois voltaremos a ele no tópico seguinte desta discussão. No momento, julgamos suficiente adiantar nosso entendimento de que a atitude de obter a satisfação de 
direitos pela via judicial pode traduzir uma postura individualista, que se aproxima do egoísmo, na medida em que serve à apropriação unilateral de bens (no caso, fundos públicos) para uso próprio, sem que a sociedade tenha a oportunidade mínima de se manifestar. $O$ fato de os mecanismos utilizados serem legais no sentido jurídico do termo, não tem o condão de tingir a conduta com as cores da eticidade.

A conclusão obtenível das considerações exaradas neste tópico até o presente momento é que, além de encontrar limites na violação do Princípio da Autonomia, como classicamente estabelecido, o Princípio da Beneficência pode também encontrar limitações na violação de direitos de terceiros, quando a ele se contrapõe o Princípio da Justiça, com cuja violação se confunde nessa circunstância. Uma outra forma de expressar esta conclusão é que, enquanto no campo da "micro-bioética" os limites de aplicação do Princípio da Beneficência são dados pela violação ao Princípio da Autonomia, quando nos situamos no contexto da "macro-bioética", àquele princípio contrapõe-se como limite o Princípio da Justiça.

Com o estabelecimento destes conceitos, estamos aptos a passar ao segundo dos quatro aspectos referidos acima.

\section{BIOÉTICA E SAÚDE PÚBLICA: A QUESTÃO DAS MACROALOCAÇÕES DE RECURSOS}

A condição de país semidesenvolvido, com enorme dívida social a ser resgatada e a conhecida limitação (ou finitude) de recursos, remetem a discussão de forma inexorável para o campo da saúde pública e mais especificamente sobre as implicações éticas necessariamente vinculadas aos critérios de tomada de decisões a respeito das alocações de recursos. Esta discussão não desconsidera o principialismo, mas admite-o, segundo entendemos, nos termos expostos no tópico anterior, conforme pretendemos demonstrar.

Com a finalidade de contextualizar a questão, faremos a seguir um breve resumo das idéias mais pertinentes a respeito deste subtema, valendo-nos para tanto, de conceitos expressos por Pessini e Barchifontaine ${ }^{7}$ e Pavonit.

Isto posto, podemos dizer que cursamos, aqui, na seara do que Pessini e Barchifontaine denominam de "macrobioética", em contraposição a uma "microbioética", a primeira mais afeiçoada aos problemas da América Latina, daí também a denominarem de bioética latino-americana ou de bioética sob uma perspectiva latino-americana.

Tanto Pessini e Barchifontaine quanto Pavoni realçam os mesmos aspectos, referindo-se à problemática da eleição de critérios de distribuição 
dos recursos do ponto de vista de sociedades que se apresentam com graus acentuados de injustiça e exclusão social e à necessidade de que as ações envolvam equidade, justiça e solidariedade. Em relação ao primeiro destes aspectos, apontam para o fato de que a simples existência de alta tecnologia e centros de cuidados médicos avançados e de excelência levantam questões referentes à discriminação e injustiça na assistência médica, sendo mais importante a questão de como se distribui o acesso a esta tecnologia do que propriamente o uso que dela se faz (sendo esta última, preocupação predominante, se não exclusiva, nas reflexões da "microbioética" ou bioética do primeiro mundo, particularmente a americana e que se vale de forma conspícua do principialismo).

Com referência ao terceiro aspecto, os dois grupos de autores expressam robusta convicção sobre a necessidade de estimular a solidariedade e suplantar o egoísmo e o individualismo, bem como a necessária participação de toda a sociedade nos mecanismos de decisão. Nenhum deles, entretanto, s.m.j., desce a considerações detalhadas sobre como entendem deva ser exercida a solidariedade no seio da sociedade, nem à forma como devam ser moldados os critérios segundo tais princípios ou ainda de que forma estaria violada a solidariedade ou exercido de forma iníqua ou exacerbada o individualismo.

Pessini e Barchifontaine, por exemplo, expressam-se no sentido de "não deixar os interesses individuais egoístas se sobreporem e calarem a voz dos outros (excluídos) e esconderem as suas necessidades", mas não dão direções sobre de que forma poderia ser obtida esta prescrição ou mesmo se, por exemplo, consideram como excluídos os grupos e pessoas beneficiários de ações judiciais com as características por nós definidas acima.

Analisando os fatos da saúde pública tal como se apresentam, Pavoni afirma que a maior parte dos critérios habitualmente utilizados tem em comum o princípio da utilidade social, na esteira do pensamento utilitarista. Criticando esta postura, cuja principal característica é a otimização da relação custo - benefício, assim se expressa esta autora: " $A$ utilização desse critério, com uma visão obtusa da análise custo - benefício, pode resultar na restrição de acesso a determinadas tecnologias de alto custo a fim de poder prover às necessidades básicas da maioria ou ainda pode levar à discriminação de grupos minoritários ${ }^{(*)}$ ou considerados pouco produtivos, como os idosos, os portadores de deficiências ou de patologias pouco prevalentes $^{(2) "}$ (grifos nossos).

Finalmente, Pessini e Barchifontaine registram que a valorização exacerbada do Princípio da Beneficência na América Latina traduz atitude pater-

(2) Seria o caso, no nosso exemplo, dos portadores da Doença de Gaucher. 
nalista e embora não o digam expressamente, o contexto permite entender que esta circunstância manifesta atraso na estruturação e uso dos direitos políticos e de cidadania.

Resumindo, a problemática bioética de países com as características da latinoamérica funda-se na necessidade da melhor distribuição de recursos limitados a uma população vítima de injustiças sociais. Nessa circunstância, privilegia as discussões sobre a ética das alocações de recursos em desfavor de discussões "microbioéticas" ou clínicas, calcadas de forma mais robusta no principialismo.

A solução do problema de uma perspectiva latino-americana passa, portanto, segundo esses autores, pelo Princípio da Justiça, entendido aqui como manifestação de equidade, solidariedade e contraposição ao individualismo e egoísmo e ainda pelo entendimento de que há um uso abusivo do Princípio da Beneficência e que tal se dá como fruto do caráter paternalista da sociedade.

Resumindo em brevíssimas palavras aqueles que consideramos os principais elementos do pensamento dos autores citados, concluímos, reiterando entretanto, que nenhum deles tece considerações sobre as formas de que se revestiriam as atitudes que não primassem pela solidariedade $e$ sentimentos de equidade e justiça, ou, mais especificamente, se não estariam ferindo tais princípios grupos que se apossassem de parte substancial de recursos públicos pela via do processo judicial ou mesmo pela via administrativa, ainda que mediante o uso de medidas lícitas. Pavoni toca explicitamente um dos pontos pertinentes a esta discussão, ao expressar seu entendimento de que o uso obtuso do critério de relação custo - benefício pode prejudicar alguns grupos mas não faz nenhuma observação sobre o modo de agir de tais grupos nem se refere à situação tratada neste texto. Não tece nenhuma consideração, também, sobre a possibilidade de que a própria relação custo - benefício acabe se tornando imprópria, mesmo de um ponto de vista estritamen te utilitarista, se a prática em questão vier efetivamente compromter a capacidade gerencial da Administração.

\section{DOS ASPECTOS JURÍDICOS ENVOL VIDOS NA QUESTÃO}

Já manifestamos na introdução a este texto, nossa compreensão de que o fundamento jurídico da situação aqui estudada calca-se, principalmente, na concepção jurisprudencial e doutrinária acerca da qualidade de exigibilidade imediata da norma constitucional. Assim, qualquer medida tendente a solucionar a situação descrita implicaria em promover mudanças na atual conformação doutrinária e jurisprudencial e eventualmente até a produção de nova positivação normativa constitucional, se as medidas anteriores não se mostrassem suficientes. 
Um outro elemento sob o qual poderia ser analisada a questão jurídica é o da natureza e poder do juiz com referência aos atos da Administração. É conhecimento banal em Direito Administrativo que ao Poder Judiciário é autorizado manifestar-se e decidir sobre a legalidade do Ato Administrativo, mas não sobre seu mérito. Entendemos que ao manifestar-se no sentido de obrigar a Administração a fornecer ao cidadão determinado recurso que o Poder Executivo ainda não havia decidido incluir no rol dos disponíveis, o juiz fere o princípio acima citado, obrigando o Administrador a tomar medidas relativas ao mérito do ato (que depende, como se sabe, de critérios de oportunidade e conveniência na visão do Administrador), e não apenas em referência à sua legalidade. Consta que na Inglaterra as leis impedem o juiz de manifestar-se neste sentido em matéria de Direito Sanitário.

Seriam necessárias, portanto, medidas que regulamentassem de forma mais clara e definida os poderes e modos de intervenção do Poder Judiciário nesta área, além das mudanças acima propostas na esfera constitucional.

Pretendemos tratar do assunto em um próximo texto.

\section{DA REPRODUÇÃO E PERPETUAÇÃO DE UM MODELO DE SAÚDE PÚBLICA ATRELADO AO MERCADO}

Sem pretender nos estender sobre o assunto, lembramos que a modernidade caracteriza-se, entre outras, pelo atrelamento do consumo ao mercado e à tecnologia, ou seja, o avanço tecnológico gera necessidades mercadológicas e, por este mecanismo, indiretamente, direciona o consumo.

No campo da saúde, é banal a noção de que o sistema de saúde sofre o impacto da constante renovação tecnológica e do mercado e tende a curvar-se às exigências deste.

A imensa maioria (quase totalidade) das ações judiciais que buscam a satisfação de direitos na área da saúde alberga deduções de direito no sentido de incorporação de nova tecnologia, havendo notório interesse da indústria médico-farmacêutica no resultado de tais ações.

Concluímos, assim, que a atividade judicial ora em estudo, não obstante seus fundamentos constitucionais baseados no direito à saúde, entendido como direito social inalienável a ponto de ser alçado ao status de direito humano de segunda geração, presta-se, irônica e contraditoriamente, à reprodução e perpetuação de um modelo de saúde atrelado aos interesses do mercado e à alucinante incorporação de nova tecnologia, tudo à revelia da vontade da sociedade. 


\section{CONCLUSÃO}

1. A ordem constitucional brasileira emanada da Constituição Federal de 1988 alçou o direito à saúde ao nível de direito constitucional.

2. Em termos da concepção principialista, o fundamento desta postura do Legislador Constitucional é o Princípio da Beneficência.

3. Considerações jurisprudenciais e doutrinárias ampliaram a aplicação da norma constitucional, consignando-lhe os atributos da aplicabilidade e exigibilidade imediatas, sobrepujando situação anterior em que tais normas eram admitidas como principiológicas, programáticas ou ainda meramente declaratórias de direitos.

4. A circunstância descrita no item anterior, associada a outros elementos da história jurídico-política recente do Brasil, permitiu o uso do processo judicial para a satisfação imediata de direitos na área da saúde, criando uma nova cultura jurídico-processual.

5. Esta atividade mostra, entretanto, um lado "perverso", constituído pelo abuso no uso do Princípio da Beneficência.

6. O uso irrefletido deste princípio pode lesar o direito de terceiros e, desta forma, violar o Princípio da Justiça.

7. A postura de reivindicar direitos constitucionais relativos à saúde via processo judicial pode configurar-se em "apossamento unilateral" de recursos públicos e nesse sentido também viola o Princípio da Justiça ao desrespeitar elementos que devem compor os critérios da escolha de alocações de recursos em países não desenvolvidos, quais sejam, a equidade e a solidariedade. Tal conduta pode ser entendida numa outra perspectiva, como manifestação de egoísmo e exacerbação do individualismo.

8. S.m.j., os doutrinadores da bioética ainda não atentaram para a possibilidade de que as circunstâncias descritas neste texto, que, a uma primeira vista (ou, "num primeiro momento", para usar um jargão "rossiano") afeiçoam-se aos princípios do exercício de direitos de cidadania, possam, entretanto, embutir uma face "perversa", constituída pelo supracitado exacerbamento do individualismo.

9. A adoção forçada de medidas distributivas desiguais que configurem discriminação positiva a favor de grupos minoritários pode ferir o Princípio da Justiça por não albergar os elementos de solidariedade e participação altruísta de toda a sociedade. Apenas a sociedade organizada por intermédio da atividade administrativa e legislativa do Estado tem legitimidade para destinar os recursos públicos, excluído necessariamente desta esfera de legitimidade o Poder Judiciário.

10. A aplicação dos Princípios do Direito e o uso do Processo Judicial para a satisfação imediata de direitos constitucionais pode, paradoxal e ironi- 
camente, reforçar o atrelamento do modelo de assistência médica aos interesses do mercado, sobretudo aos interesses da indústria médico-farmacêutica.

11. A correção desta situação implica em adotar medidas de positivação legislativa que deixem claros os limites do juiz no que tange à apreciação dos atos do Administrador na área da determinação dos serviços dispensados pelo SUS, reinterpretando, inclusive, o alcance da norma constitucional.

12. Devem ser tomadas medidas que prevejam a satisfação de grupos minoritários ainda que portadores de doenças pouco prevalentes e/ou de custos muito elevados, mas a determinação dos destinos dos recursos públicos na área da saúde deve ser procedida com a participação de toda a sociedade, não se excluindo a possibilidade de serem procedidas medidas administrativas, políticas e até judiciais (aqui sim!) no sentido de amoldar os preços de determinados insumos de saúde praticados pela indústria, às necessidades da população e capacidade financeira e orçamentária do Sistema Único de Saúde.

\section{REFERÊNCIAS BIBLIOGRÁFICAS}

1. DALLARI SG. O Direito à Saúde. Revista de Saúde Pública, v. 22 I, n. 1, pp. 5763, 1988.

2. O papel do município no desenvolvimento de políticas de saúde. Revista de Saúde Pública, v. 25, n. 5, pp. 401-405, 1991.

3. Os Estados Brasileiros e o Direito à Saúde. São Paulo. Hucitec, 1995.

4. KIPPER DJ, CLOTET J. Princípios da Beneficência e Não Maleficência. In: COSTA SIF, GARRAFA V, OSELKA G. (org.) - Iniciação à Bioética. Brasília: CFM, 1998.

5. LUCARELLI LA. Decisões Judiciais e suas implicações na Secretaria de Saúde de São Paulo. Monografia de Conclusão de Curso - Curso de Economia e Gestão em Saúde - Centro Paulista de Economia da Saúde (CPES) Universidade Federal de São Paulo. Material ainda não apresentado.

6. PAVONI EL, CZ. Desafios do Próximo Milênio. In: CLOTET J. (org.) Bioética. Porto Alegre: EDIPUCRS, 2001.

7. PESSINI L, BARCHIFONTAINE CP. Bioética: do Principialismo a uma Busca de uma Perspectiva Latino-Americana. In: COSTA SIF, GARRAFA V, OSELKA G. (org.) Iniciação à Bioética. Brasília: CFM, 1998.

8. PITTELLI SD. O Poder Normativo do Conselho Federal de Medicina e o Direito Constitucional à Saúde. Revista de Direito Sanitário, v. 3, n. 1, pp. 38-59, 2002.

9. SILVA JA. Curso de Direito Constitucional Positivo. 17. ed. São Paulo: Malheiros Editores, 2000.

10. SIQUEIRA JE. O Princípio da Justiça. In: COSTA SIF, GARRAFA V, OSELKA G. (org.) Iniciação à Bioética. Brasília: CFM, 1998. 